\title{
A pacífica ascensão da China: perspectivas positivas para o futuro?*
}

ANTÔNIO JOSÉ ESCOBAR BRUSSI ${ }^{* *}$

O bom leitor de Adam Smith em Pequim - bom por aceitar a recomendação do autor de lê-lo por inteiro - não deixará de ser intelectualmente estimulado e, em muitos casos, surpreendido, durante o itinerário dessa leitura. A começar pelo intrigante título. A meu ver, Adam Smith em Pequim apresenta um duplo e complementar sentido. O primeiro, extraído das páginas de A Riqueza das Nações, refere-se à reiterada referência de Smith a respeito do padrão chinês para a maturidade econômica como "o progresso natural para a opulência" ou "o curso natural das coisas”, de acordo com suas próprias palavras. Aqui, Smith exalta o virtuosismo do capital investido domesticamente - primeiramente na agricultura e, em seguida, no comércio varejista - como aquele que produz os efeitos mais sólidos e duradouros pelas conseqüências positivas para o crescimento do salário e da renda nacional. Contrasta o caminho chinês com o holandês, o caso "extremo de pais que seguiu o caminho europeu para a maturidade econômica.... (percurso) não natural e retrógrado ( $(\mathrm{p}$. 57) por assentar-se no grande comércio atacadista que "parece não ter residência fixa e pode vagar de um lugar para outro em busca de lugar onde possa comprar barato e vender caro." (p. 59)

Por outro lado, o segundo sentido desse atrativo título está mais identificado a uma certa continuidade daquele padrão virtuoso - depois de mais de um século de interregno - e das surpreendentes conquistas que a China vem progressivamente alcançando na economia e na política mundiais. Seriam, ao mesmo tempo, uma oportuna lembrança e um devido reconhecimento que Arrighi presta à antecipação smithiana da ascensão chinesa e das vantagens de se utilizar a maior parte do capital primeiramente na agricultura, depois nas manufaturas e, por fim, no comércio exterior. Adicione-se a essa interessantíssima referência a Smith uma segunda, de autoria de Robert Heilbroner, segundo a qual ele "pode bem ser um dos mais amplamente citados e mais raramente lidos de todos os mestres economistas do passado". (p. 42) e a oportunidade que Arrighi mais uma vez aproveita para apresentar três mitos que circundam o legado de Smith: "1) que ele foi um teórico

* ARRIGHI, Giovanni. Adam Smith in Beijing: Lineages of the Twenty-first Century. London/New York: Verso, 2007, 418 p., ISBN 978-1-84467-104-5.

** Professor do Instituto de Ciência Política da Universidade de Brasília - UnB (brussi@rudah.com.br). 
e defensor da "auto-regulação" dos mercados; 2) que ele foi um teórico do capitalismo visto como um motor 'incessante’ de expansão econômica e, 3) que ele foi um teórico e defensor do tipo de divisão do trabalho que ocorria na fábrica de alfinetes descrita no primeiro capitulo da Riqueza das Naçôes" (p. 42). Posteriormente, a desconstrução desses mitos fundamentará o detalhamento das peculiaridades da economia política da China e de suas potencialidades.

Após longa e elaborada argumentação teórica onde compara e contrapóe de modo similarmente original Smith, Marx e Schumpeter, Arrighi continua a desenvolver o tema que há bastante tempo vem ocupando suas reflexões. Ele mesmo contabiliza que o livro na verdade começou nos anos 1970, embora possa ser lembrado que suas reflexões mais sistemáticas como as desenvolvidas em torno do estatuto teórico e empírico da hegemonia na economia-mundo, núcleo fundamental do presente trabalho ora resenhado, tenham se iniciado no início dos anos 1990, após quase uma década dedicada à problemática da semiperiferia. A rigor, foi a partir da busca por mais consistência para o conceito de semiperiferia que ocorreu o presente desdobramento, quer na direção dos estudos sobre hegemonia - um dos cimentos político-ideológicos do sistema mundial - quer na da crescente preocupação com os estados e as economias do leste asiático, vistos em um primeiro momento como promissores candidatos à mobilidade ascendente e posteriormente reconhecidos como tendo completado ao menos um movimento progressivo nesse rígido sistema de estratificação que é a economia-mundo capitalista.

Tomando como ponto de partida os achados de estudos anteriores, notadamente em $O$ Longo Século XX e em Caos e Governabilidade no Moderno Sistema Mundo - este em co-autoria com Beverly Silver - ambos traduzidos para o português, o autor desenvolve uma longa e detalhada comparação das três últimas décadas do século XX e os primeiros anos do XXI, com períodos precedentes de crise de hegemonia, a saber, a crise da hegemonia holandesa, durante o século XVIII - compreendendo o longo período entre a Guerra da Sucessão Espanhola (1701-14) e a Quarta Guerra Anglo-Holandesa (1780-84) - e a crise da hegemonia inglesa, de 1870 ao início dos anos 1930. A partir da análise detalhada do que é peculiar em cada "momento" das hegemonias pretéritas e do que se repetiu, com que grau de importância e com que ordem de abrangência, Arrighi identifica as peculiaridades da hegemonia americana, iniciada ao final da Segunda Guerra Mundial e, com minúcia de detalhe, reporta sua incontrastável decadência.

Do mesmo modo que em vários estudos das Relaçóes Internacionais, o conceito de hegemonia utilizado por Arrighi provém do conhecido referencial gramsciano, que o edifica a partir da capacidade de um grupo apresentar-se durante um determinado período como portador do interesse geral de uma dada sociedade. Ao transpor essa peculiar capacidade de liderança ao ambiente do sistema interestatal, entretanto, Arrighi desdobra a ascendência que um estado exerce sobre os demais em duas direçôes designadoras de dois tipos de fenômenos. Por um lado, temos um estado que "em virtude de seu desempenho...se torna modelo 
para outros estados imitarem-no e, a partir daí, serem atraídos para sua própria rota de desenvolvimento". Neste caso, estamos falando de liderança. Por outro lado, hegemonia vai destacar que "o estado dominante lidera o sistema de estados em uma desejada direção e, ao fazer isso, é amplamente percebido como portadorldefensor do interesse geral." (ARRIGHI \& SILVER, 1999:27).

No entanto, se atualmente não se observa qualquer estado assumindo tal posição e sendo reconhecido no sistema interestatal por essa tarefa, também não se pode identificar o surgimento de radicalizações competitivas do tipo de corrida armamentista ou de paz armada, como em outros momentos no passado. Se a concentração do poder militar em um estado, se os esforços dos países centrais para uma certa convergência e se a unidade do mercado mundial têm evitado aquela rivalidade belicosa de outros tempos, por outro lado essas características do momento atual não permitem excluir de um cenário futuro a crescente expansão de tensões, como as que podem irromper em caso de uma ampla e profunda depressão econômica mundial. De acordo com o autor, portanto, tal contexto está marcado pelo irrecuperável declínio da credibilidade previamente desfrutada pelos Estados Unidos como portador/defensor do interesse geral do sistema interestatal. Essa descrença foi provocada inicialmente pelo fracasso militar no Vietnã e reforçada recentemente pelos sucessivos reveses americanos no mundo muçulmano, especialmente no Iraque. Além disso, o processo de liberalização multilateral do comércio e de movimento de capitais acabou limitando as açóes do poder americano, especialmente no âmbito financeiro. Por fim, "o maior de todos os fracassos do projeto imperial neoconservador: o de impedir que a China se transformasse em um novo centro potencial da economia política global" (p. 203). Assim, ao reconhecermos a existência de um estado que concentra um poder militar sem rival e ao admitirmos que esse estado não carrega mais a bandeira da credibilidade mundial, especialmente pelos sucessivos fracassos político-militares sofridos nos últimos quarenta anos, estamos frente a uma situação que o autor caracteriza como de dominação sem hegemonia.

Embora nessa moldura internacional a China seja percebida como a grande beneficiária da cruzada antiterrorista desencadeada pelos Estados Unidos desde os anos 1990, o autor aponta três propostas que visam conter essa "pacífica ascensão" que caracteriza a provável caminhada chinesa para o perímetro do centro da economia mundial. Ainda que radicalmente contrastantes, as alternativas neoconservadoras desenvolvidas por Kaplan, Kissinger e Pinkerton são distantes uma das outras e independentes de apoios partidários mostrando, com isso, como o tema tem sido controvertido mesmo no seio do pensamento conservador.

Tomando como referência as tensões e conflitos surgidos no passado por disputas por hegemonia no sistema interestatal, Kaplan antecipa que a emergência da China como uma superpotência é inevitável e que, conseqüentemente, conflitos de interesses com os Estados Unidos serão incontornáveis. Para enfrentar com vantagem essa ameaça, os EUA devem buscar: 1) reforçar um equilíbrio regional de poder evitando a todo custo aventuras militares na região e 2) gerenciar riscos a 
partir de uma "estratégia bismarckiana de contenção centrada no Comando Americano do Pacífico, conhecido como PACON." (p.285) Aqui, nessa nova Guerra Fria, busca-se inspiração na bem-sucedida contenção e posterior vitória sobre a ex-União Soviética que a construção de um equilíbrio de poder a partir da OTAN ajudou a organizar. Ressalte-se que no caso chinês essa contenção limita-se ainda a uma dimensão asiática.

A proposta de Kissinger é radicalmente diferente por não pressupor como inevitável uma confrontação dos EUA com a China, embora concorde que "o centro de gravidade dos interesses do mundo está mudando do Atlântico... para o Pacifico." (p. 289). Partindo do princípio de que uma ameaça militar chinesa é inexistente ou, na pior das hipóteses ainda muito distante, Kissinger entende que o interesse americano será muito mais facilmente alcançado a partir da cooperação com a China. Ao mesmo tempo, adverte que a China não é a Alemanha nem a Rússia, seja por razões históricas (o país existe com autogoverno há quatro mil anos) seja por motivos político-ideológicos, como demonstrado pelos ensinamentos de ação estratégica de Sun Tzu ou pelos quatro não e os quatro sim tão enfáticos do Presidente Hu Jingtao, por exemplo (não à hegemonia, à força, a blocos e à corrida armamentista; e sim à construção da confiança, a reduzir as dificuldades, a desenvolver a cooperação e a evitar a confrontação). (p. 292) Não é por outro motivo que a posição realista de Kissinger "é extraordinariamente semelhante à doutrina chinesa de heping jueqi (literalmente emergir precipitadamente de modo pacifico)". (p. 291) Problemas com a doutrina chinesa e com a de Kissinger existem nos dois lados. Do lado americano, a existência de longa e disseminada "sinofobia" vem sendo mais recentemente reforçada pelas tentativas chinesas de adquirir empresas petrolíferas nos EUA, o que tem aumentado as apreensões do eleitorado americano. Do lado chinês, existem restriçōes de dentro e de fora do Partido quer quanto aos sentidos contidos na idéia de emergir quer quanto às conseqüências do que pode ser entendido por de modo pacífico. No primeiro caso, porque pode difundir o sentimento de ameaça e no segundo pelas atitudes agressivas que podem estimular no comportamento do Japão e de Taiwan.

Do mesmo modo que Kissinger, James Pinkerton é um duro crítico da estratégia de contenção militar de Kaplan. No entanto, ele é ainda mais crítico da proposta 'kissingeriana' de acomodação. No primeiro caso porque uma coalizão suficientemente ampla para tal enfrentamento com a China - nos moldes da organizada para derrotar as aspirações alemãs - é hoje totalmente inviável. Por outro lado, a principal restrição à posição cooperativa advém das consequiências que o aprofundamento do outsourcing (aquisição no exterior de peças para cortar custos), por si mesmo um fator de aproximação EUA/China, pode provocar na capacidade produtiva americana de material bélico. E esse enfraquecimento potencial é inaceitável aos falcóes de Washington. Em tal contexto, a proposta que Pinkerton apresenta é a de uma estratégia de duas vertentes (two pronged strategy) que estimularia um equilíbrio de poder entre as atuais potências asiáticas (Índia, China e Japão) e outros tigres que porventura surgirem. Ao invés do enfrentamento direto, os Estados Unidos deveriam colocar um contra os outros. 
Arrighi encontra uma feliz denominação latina para essa estratégia de beneficiarse com a luta dos outros: tertius gaudens (o terceiro alegra-se).

Depois de longa crítica a cada uma dessas propostas, das quais um destacado argumento é apresentado como "a grande muralha de ignorância a respeito da China", o autor desenvolve longa e detalhada interpretação da economia política chinesa, identificando as origens internas e externas da dinâmica de sua ascensão.

Por fim, o autor retorna a algo apresentado logo na introdução e que foi propositalmente deixado de lado até agora nesta resenha: a questão central de todo o seu trabalho. Afinal, ao iniciar seu percurso investigativo, Arrighi perguntava se a "ascensäo chinesa com todas suas inconsistências e possiveis reviravoltas futuras... (poderia ser entendida) como mensageira de maior igualdade e respeito mútuo entre europeus e não europeus... (ponto que) que Smith antecipou e defendeu 230 anos atrás." (p. 379) No final de seu trabalho conclui que a análise indica que sim, porém com importantes ressalvas. Como verdadeira vencedora da guerra americana contra o Terror, a China vem crescentemente avançando sobre a posição anteriormente ocupada pelos Estados Unidos na Ásia de tal modo que a expressão Consenso de Pequim, cunhado por Joshua Cooper Ramo, aponta o exemplo chinês para outras nações do mundo "não simplesmente para desenvolverem-se mas para integrarem-se na ordem internacional de modo a permitir que sejam verdadeiramente independentes para protegerem seu modo de vida e (suas) escolhas politicas." (p. 379)

O livro termina advertindo que o caminho chinês de modo algum é sem percalços. Questôes ambientais e redistributivas são partes muito atuais das tensôes que o rápido crescimento fez aflorar na economia e na sociedade chinesa. Desse modo, se a reorientação de rumos em andamento

“...conseguir reavivar e consolidar as tradiçōes da China de desenvolvimento auto centrado e baseado no mercado, de acumulação sem desapropriação, de mobilização de recursos humanos ao invés dos não humanos e de governo através da participação das massas na formulação de políticas, então existem chances para que a China esteja em condiçōes de contribuir decisivamente para a emergência de uma comunidade de civilizaçōes verdadeiramente respeitadora de diferenças culturais. Mas, se a reorientação fracassar, a China pode muito bem transformar-se em um novo epicentro de caos social e político que facilitarão as tentativas do Norte de restabelecer uma dominação global em desintegração ou, para parafrasear uma vez mais Schumpeter, que contribuirão para que a humanidade queime-se nos horrores (ou glórias) da escalada de violência que tem acompanhado a liquidação da ordem mundial estabelecida pela Guerra Fria.” (p. 389)

Recebido em 21 de abril de 2008

Aprovado em 18 de junho de 2008

\section{Referência bibliográfica}

ARRIGHI, G. \& SILVER, B. (1999). Chaos and Governance in the Modern World System, University of Minnesota Press, Minneapolis. 